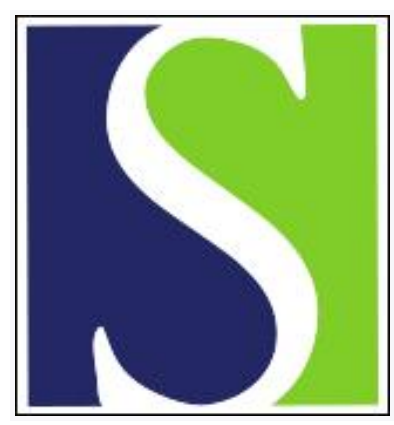

Scand J Work Environ Health 2002;28(1):5-11

https://doi.org/10.5271/sjweh.640

Issue date: Feb 2002

Adverse reproduction outcomes among employees working in biomedical research laboratories

by Wennborg H, Bonde JP, Stenbeck M, Olsen J

Affiliation: Department of Biosciences, Unit of Environmental Medicine, CNT, Novum Research Park, Karolinska Institute, SE-141 57

Huddinge, Sweden. heelena.wennborg@biosci.ki.se

Key terms: adverse reproduction outcome; biomedical research laboratory; birthweight; employee; laboratory work; postterm; preterm birth; solvent

This article in PubMed: www.ncbi.nlm.nih.gov/pubmed/11871853






\title{
Adverse reproduction outcomes among employees working in biomedical research laboratories
}

\author{
by Helena Wennborg, PhD, ${ }^{1,2}$ Jens Peter Bonde, PhD, ${ }^{3}$ Magnus Stenbeck, PhD, ${ }^{4}$ Jørn Olsen PhD ${ }^{2}$
}

\begin{abstract}
Wennborg H, Bonde JP, Stenbeck M, Olsen J. Adverse reproduction outcomes among employees working in biomedical research laboratories. Scand J Work Environ Health 2002;28:5-11.

Objectives The aim of the study was to investigate reproductive outcomes such as birthweight, preterm births, and postterm births among women working in research laboratories while pregnant.

Methods Female university personnel were identified from a source cohort of Swedish laboratory employees, and the database was linked to the medical birth register. The first births of the women were included in the analysis, 249 pregnancies among the women with laboratory work and 613 pregnancies among the women without laboratory tasks. Information about exposure to various laboratory agents was obtained from a previous questionnaire investigation at the research group level according to a specific definition. The ponderal index and ratio between observed and expected birthweights were calculated. Logistic regression models were used for analyses of dichotomous outcomes (preterm, postterm and birthweight).

Results Exposure to laboratory work with solvents was associated with an increased risk of preterm births, the estimated odds ratio (OR) being $3.4(1.0<95 \%$ confidence interval < 11.9). An association with work with bacteria was also observed for postterm births (OR 2.7, $1.0 \leq 95 \%$ confidence interval $<7.4$ ).

Conclusions There was a slightly elevated risk for some reproductive outcomes among the women working with certain laboratory tasks, specifically for preterm and postterm births in relation to work with solvents and bacteria.
\end{abstract}

Key terms birthweight, laboratory work, postterm, preterm, solvents.

There is a consensus that women should be able to work during pregnancy, and therefore workplaces should be free from reproductive hazards. To make a proper risk assessment, quantitative measures of risk by means of epidemiologic studies of, for example, reproductive failures are needed (1-3). These studies must be continuously updated since the occupational exposures change.

Employees in biomedical research laboratories are often in contact with several putative carcinogens and fetotoxic agents such as solvents, radioactive isotopes, and microorganisms, and new laboratory techniques have been introduced. Recombinant DNA (deoxyribonucleic acid) techniques, for instance, started to gain widespread use in the 1980s, and the reproductive health of personnel working with these techniques has not been extensively studied. The potential reproductive hazards for laboratory personnel have triggered a discussion about work safety and regulations (4).
Work with physical, chemical, and microbiological agents does not necessarily mean that a pregnant laboratory employee is at increased risk of reproductive failure. Risk assessment therefore requires empirical data. In this study we investigated outcomes such as preterm and postterm births and indicators of fetal growth in a population of Swedish female laboratory employees.

\section{Subjects and methods}

\section{Study base and cohort information}

We identified female university employees from a source cohort of Swedish university personnel in 1970 1989. More information on recruitment and exposure assessment in this cohort is given in a study on cancer mortality in biomedical research laboratories (5). The

1 Department of Biosciences, Novum Research Park, Karolinska Institutet, Huddinge, Sweden.

2 The Danish Epidemiology Science Centre, University of Aarhus, Aarhus, Denmark.

3 Department of Occupational Medicine, Aarhus University Hospital, Aarhus, Denmark.

4 Centre for Epidemiology, The National Board of Health and Welfare, Stockholm, Sweden.

Reprint requests to: Dr Helena Wennborg, Department of Biosciences, Unit of Environmental Medicine, CNT, Novum Research Park, Karolinska Institutet, SE-141 57 Huddinge, Sweden. [E-mail: helena.wennborg @ biosci.ki.se] 
women in our study had been employed for more than 1 year, and at least $50 \%$ worked full-time or more in departments with biomedical research as their main activity ( $\mathrm{N}=2676)$. As a comparison group, female personnel in the faculties of social sciences and natural sciences (mathematics, law and economics, $\mathrm{N}=1147$ ) were used.

Data from employee records were extracted for age, worktasks, concurrent job titles, and calendar time periods. If an employee had a leave of absence of six months or longer, this absence was noted, as well as a change of workplace and dates for the start and end of all work periods.

The database was linked to the Medical Birth Register at the Centre for Epidemiology, Swedish National Board of Health and Welfare, and the linkage resulted in data on 3719 children born in 1973 or later. Of the pregnancies obtained after the linkage, 1559 were first

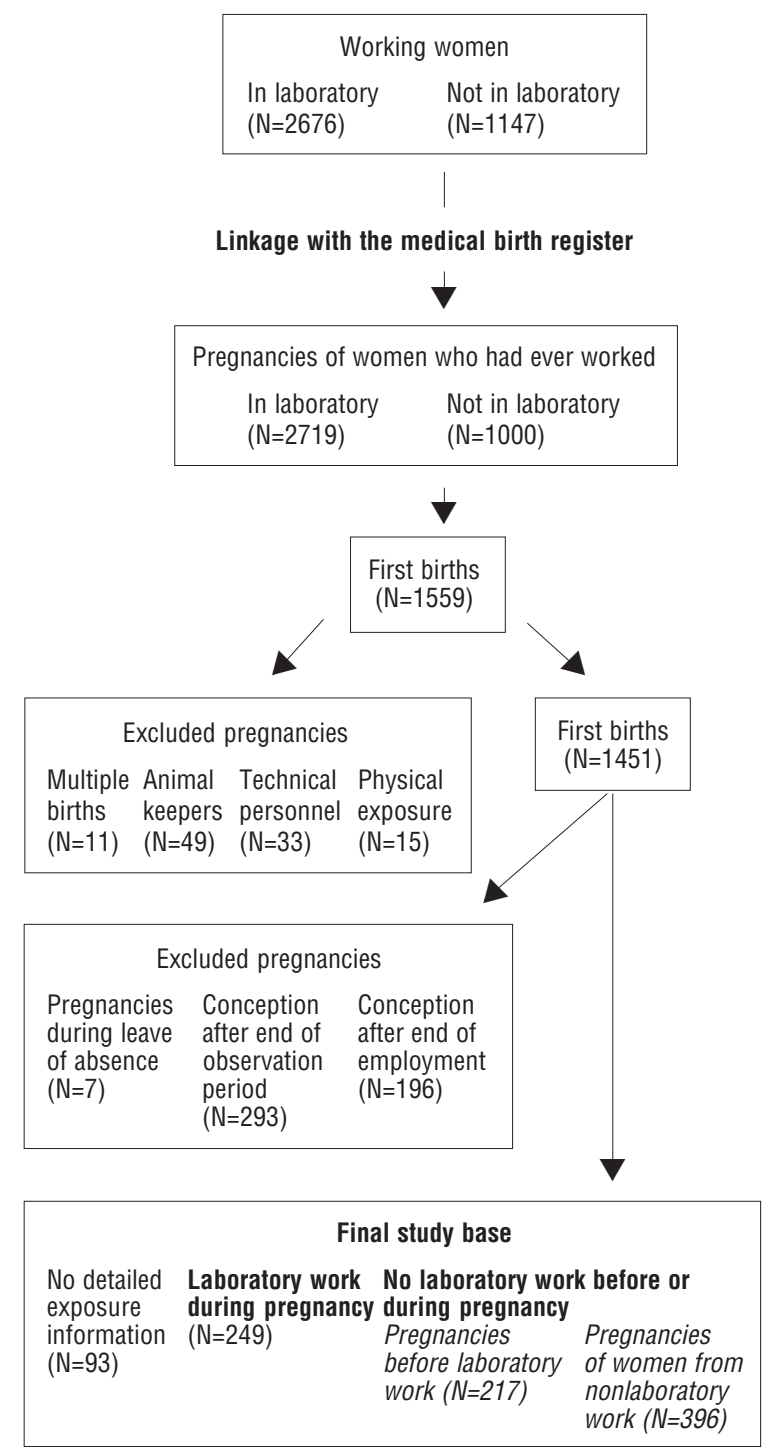

Figure 1. Identification of the study groups. births. Multiple births $(\mathrm{N}=11)$, pregnancies of women working as animal keepers $(\mathrm{N}=49)$ or in technical tasks without laboratory work ( $\mathrm{N}=33$ ), and pregnancies of employees with only physical exposures $(\mathrm{N}=15)$ among the first births were excluded $(\mathrm{N}=108)$ in order to control confounding from other possible harmful exposures (figure 1). Births were also excluded if both the conception and the delivery took place during a leave of absence from laboratory work $(\mathrm{N}=7)$. We also excluded pregnancies with conception after the end of the observation period in $1989(\mathrm{~N}=293)$, as well as pregnancies with conception occurring at or after the end of employment but before the end of the observation period $(\mathrm{N}=196)$. The remaining first births during the period 1973-1989 were included in the study base ( $\mathrm{N}=955)$. For 93 (9.7\%) of the pregnancies of women in laboratory work, no detailed exposure information was obtained in the questionnaire. Therefore, $862(90.3 \%)$ pregnancies were left with occupational exposure information with a proportion of $53 \%$ male and $47 \%$ female infants.

The analyses included exclusively the first births of women who were employed at a laboratory department at the time of conception and who were working directly with laboratory tasks in the exposed pregnancies groups $(\mathrm{N}=249)$. The outcome of first birth pregnancies of those working at a nonlaboratory department were defined as unexposed $(\mathrm{N}=396)$, together with the first births of women who started their employment in a laboratory department after the pregnancy, denoted as "students" (N=217). Information about possible confounding factors, such as previous pregnancies not resulting in a live birth, earlier reproductive experiences, diseases, and smoking, was were obtained from the Medical Birth Registry.

\section{Exposure assessment}

The exposure information was collected by means of questionnaires sent to the heads of each research group in the university departments. If the head found that the work methods used by the personnel in his or her group differed notably, the research group was subdivided into smaller groups, and the heads of each of these groups answered the questionnaire separately. The questionnaires had questions on biological, chemical, and physical agents commonly used in laboratory work and questions on specific laboratory techniques such as recombinant DNA techniques and cell culture techniques. Agents and techniques were identified from manuals for laboratory work (6), and several scientists working in different areas of biomedical research took part in the development of the questionnaire. The use of exposure agents was requested in 5-year periods. If an employee had worked only 1 year, the specific agents or techniques used in the research group during the concurrent 5 -year period were applied as exposure data for this 
person. The questionnaire response rate was $67 \%$ for personnel from laboratory departments and $63 \%$ for those from nonlaboratory departments.

In our study, information existed for each 5-year period for the following exposures: laboratory work, use of solvents, use of carcinogens, according to the 1,2A, and $2 \mathrm{~B}$ classifications of the International Agency for Research on Cancer (IARC) [IARC list of evaluations (1998), http://193.51.164.11/monoeval/grlist.htm], use of DNA and RNA (ribonucleic acid), work with animals, recombinant DNA techniques, radioactive isotopes, and cell cultures. Information about use during a 10-year period was collected for different microorganisms, except for the use of bacteria in recombinant techniques, for which data were obtained for 5-year periods (7). Work with animals and cell techniques can be considered potential risk factors since eukaryotic cells may possibly harbor retroviruses $(8,9)$. DNA and RNA were not expected to be teratotoxic as biological compounds, but, during the preparation of DNA and RNA, solvents such as phenol, chloroform, and isoamylalcohol, as well as ethidium bromide, are routinely used (6). Work with recombinant DNA techniques includes both procedures with solvent use and contact with bacteria (6).

\section{Definitions of pregnancy outcomes}

The ponderal index (birthweight in kilograms / birth length raised to the power of 3 in cubic meters) and an expected birthweight were calculated for each pregnancy, and the ratio between the observed and expected birthweight was derived (10).

Preterm birth was defined as a birth with a gestational age of less than 37 weeks, and postterm birth was defined as birth at a gestational age of 42 weeks or longer. Gestational age was calculated using the date of last menstruation. If this information was lacking or differed by more than 2 weeks from the ultrasound measurement, the ultrasound estimate was used.

\section{Statistical analyses}

In the statistical analyses, we included only the first pregnancy that resulted in a birth and partly or completely overlapped the observed time. Each outcome was analyzed separately. Hence the unit of observation was the pregnancy. Analyses were performed by logistic multiple regression models for the four dichotomous outcomes (11) birthweight < 2500 grams, birthweight $>4000$ grams, preterm births, and postterm births.

Exposure to "research work with animals and cell techniques" was combined in the analyses. Work with DNA and RNA were omitted from the analyses; this step pertained to a small number of women who were primarily exposed to both of these agents at the same time. The analyses were adjusted for the potential confounding effects of the mother's age and previous pregnan- cies not resulting in a live birth, as well as smoking and gestational age. A covariate was considered as a confounder and included in the analysis when the crude odds ratio (OR) differed from the adjusted odds ratio by more than $10 \%$. Data on smoking were, however, missing for $68 \%$ (table 1), and therefore the classifications "smokers", "nonsmokers" and "missing data" were used, and the parameter was included in the analyses. The logistic procedure in the software package STATA 6.0 was used to perform the analyses (12). This project was approved by the Ethics Committee of the Karolinska Institutet and by the Swedish Data Inspection Board.

\section{Results}

The characteristics of the mothers are shown in table 1 according to the type of work during the first pregnancy. Women not performing laboratory work were more often researchers, as well as younger and older primiparas. The proportions of caesarian sections and previous pregnancies not leading to birth were higher among the laboratory employees.

Table 1. Mother's characteristics according to laboratory work exposure and employment during pregnancy.

\begin{tabular}{|c|c|c|c|c|}
\hline \multirow[t]{2}{*}{ Characteristics } & \multicolumn{2}{|c|}{$\begin{array}{c}\text { Laboratory } \\
\text { work } \\
(\mathrm{N}=249)\end{array}$} & \multicolumn{2}{|c|}{$\begin{array}{c}\text { Nonlaboratory } \\
\text { work } \\
(\mathrm{N}=613)\end{array}$} \\
\hline & $\mathrm{N}$ & $\%$ & $\mathrm{~N}$ & $\%$ \\
\hline \multicolumn{5}{|l|}{ Occupation } \\
\hline Scientist & 53 & 21.3 & 160 & 26.1 \\
\hline Graduate student & 39 & 15.7 & 28 & 4.6 \\
\hline Laboratory technician & 157 & 64.9 & - & . \\
\hline Administration and secretary & - & . & 259 & 42.2 \\
\hline Cleaning personnel & - & . & 17 & 2.8 \\
\hline Student & - & . & 149 & 24.3 \\
\hline \multicolumn{5}{|l|}{ Mother's age } \\
\hline$<24$ years & 10 & 4.0 & 76 & 12.4 \\
\hline 24-33 years & 216 & 86.8 & 470 & 76.7 \\
\hline$>33$ years & 23 & 9.2 & 67 & 10.9 \\
\hline \multicolumn{5}{|l|}{ Smoking during pregnancy a } \\
\hline Yes & 13 & 8.7 & 17 & 14.1 \\
\hline No & 105 & 91.7 & 104 & 85.6 \\
\hline \multicolumn{5}{|l|}{$\begin{array}{l}\text { Previous pregnancy } \\
\text { not resulting in a live birth }\end{array}$} \\
\hline 0 & 223 & 89.6 & 568 & 92.7 \\
\hline$\geq 1$ & 26 & 10.4 & 45 & 7.3 \\
\hline \multicolumn{5}{|l|}{ Mother's weight gain b } \\
\hline$<6 \mathrm{~kg}$ & 2 & 1.9 & 3 & 2.3 \\
\hline $6-15 \mathrm{~kg}$ & 75 & 69.4 & 75 & 58.7 \\
\hline $16-25 \mathrm{~kg}$ & 31 & 28.0 & 47 & 36.7 \\
\hline$>25 \mathrm{~kg}$ & - & $\cdot$ & 3 & 2.3 \\
\hline \multicolumn{5}{|l|}{ Caesarian section } \\
\hline Yes & 38 & 15.3 & 52 & 8.5 \\
\hline No & 211 & 84.7 & 561 & 91.5 \\
\hline
\end{tabular}

a $\mathrm{N}=587$ missing.

${ }^{b} \mathrm{~N}=626$ missing. 
The birth outcomes for the exposed and unexposed are listed in table 2 . The mean birthweight was approximately the same across the groups. Except for the case of perinatal death, there was a slightly higher, albeit nonsignificant, proportion of negative reproductive outcomes among the women working with laboratory tasks.
There were only small, nonsignificant differences in the ponderal indices or ratios between the observed and expected birthweights of the exposed and unexposed pregnancies (data not shown).

Laboratory work in general showed unadjusted odds ratios of 1.2 [95\% confidence interval $(95 \% \mathrm{CI}$ )

Table 2. Outcomes and numbers of first births among female university employees according to laboratory work exposure during pregnancy.

\begin{tabular}{|c|c|c|c|c|c|c|c|c|c|c|c|c|}
\hline \multirow[t]{3}{*}{ Characteristic } & \multicolumn{6}{|c|}{ Laboratory work (N=249) } & \multicolumn{6}{|c|}{ Nonlaboratory work ( $\mathrm{N}=613$ ) } \\
\hline & \multirow[t]{2}{*}{ N } & \multirow[t]{2}{*}{$\%$} & \multicolumn{2}{|c|}{ Grams } & \multicolumn{2}{|c|}{ Days } & \multirow[t]{2}{*}{ N } & \multirow[t]{2}{*}{$\%$} & \multicolumn{2}{|c|}{ Grams } & \multicolumn{2}{|c|}{ Days } \\
\hline & & & Mean & SD & Mean & SD & & & Mean & SD & Mean & SD \\
\hline Birthweight a & 249 & . & 3413.1 & 609.2 & . & . & 612 & . & 3426.1 & 527.7 & . & . \\
\hline Gestational age ${ }^{b}$ & 248 & . & . & . & 280.7 & 16.8 & 612 & . & . & . & 281.3 & 12.6 \\
\hline \multicolumn{13}{|c|}{ Birthweight $>4000 \mathrm{~g}$ a } \\
\hline Yes & 31 & 12.5 & . & . & . & . & 66 & 10.8 & . & . & . & . \\
\hline No & 218 & 87.5 & . & . & . & . & 546 & 89.2 & . & . & . & . \\
\hline \multicolumn{13}{|c|}{ Birthweight $<2500 \mathrm{~g} \mathrm{a}$} \\
\hline Yes & 13 & 5.2 & . & . & . & . & 20 & 3.3 & . & . & . & . \\
\hline No & 236 & 94.8 & . & . & . & . & 592 & 96.7 & . & . & . & $\cdot$ \\
\hline \multicolumn{13}{|l|}{ Preterm ${ }^{b}$} \\
\hline Yes & 13 & 5.2 & . & . & . & . & 25 & 4.1 & . & . & . & . \\
\hline No & 235 & 94.8 & . & . & . & . & 587 & 95.9 & . & . & . & . \\
\hline \multicolumn{13}{|l|}{ Postterm ${ }^{b}$} \\
\hline Yes & 38 & 15.3 & . & . & . & . & 86 & 14.0 & . & . & . & . \\
\hline No & 210 & 84.7 & . & . & . & . & 526 & 86.0 & . & . & . & $\cdot$ \\
\hline \multicolumn{13}{|l|}{ Perinatal death } \\
\hline Yes & 3 & 1.2 & . & . & . & . & 10 & 1.6 & . & . & . & . \\
\hline No & 246 & 98.8 & . & . & . & . & 603 & 98.4 & . & . & . & . \\
\hline \multicolumn{13}{|c|}{ Apgar score: 1 minute ${ }^{c}$} \\
\hline $0-4$ & 8 & 3.3 & . & . & . & . & 15 & 2.5 & . & . & . & . \\
\hline $5-7$ & 19 & 7.8 & . & . & . & . & 46 & 7.8 & . & . & . & . \\
\hline $8-10$ & 217 & 88.9 & . & . & . & . & 530 & 89.7 & . & . & . & $\cdot$ \\
\hline
\end{tabular}

a $\mathrm{N}=1$ missing.

${ }^{b} \mathrm{~N}=2$ missing.

${ }^{c} \mathrm{~N}=27$ missing

Table 3. Estimated odds ratios (OR) with $95 \%$ confidence intervals $(95 \% \mathrm{CI})$ for high and low birthweight and preterm and postterm births - model I according to laboratory work in general and model II including several specific laboratory exposures. ${ }^{\mathrm{a}}\left(A=\right.$ number $^{\mathrm{a}}$ exposed pregnancies, $B=$ number of cases among the exposed, DNA = deoxyribonucleic acid)

\begin{tabular}{|c|c|c|c|c|c|c|c|c|c|c|c|c|c|c|c|c|}
\hline \multirow[t]{3}{*}{ Work exposure } & \multicolumn{4}{|c|}{ Birthweight $>4000 \mathrm{~g}^{\mathrm{b}}$} & \multicolumn{4}{|c|}{ Birthweight < $2500 \mathrm{~g}^{b}$} & \multicolumn{4}{|c|}{ Preterm births ${ }^{c}$} & \multicolumn{4}{|c|}{ Postterm births ${ }^{c}$} \\
\hline & \multicolumn{2}{|c|}{ Cases } & \multirow[t]{2}{*}{$\mathrm{OR}$} & \multirow[t]{2}{*}{$95 \% \mathrm{Cl}$} & \multicolumn{2}{|c|}{ Cases } & \multirow[t]{2}{*}{$\mathrm{OR}$} & \multirow[t]{2}{*}{$95 \% \mathrm{Cl}$} & \multicolumn{2}{|c|}{ Cases } & \multirow[t]{2}{*}{$\mathrm{OR}$} & \multirow[t]{2}{*}{$95 \% \mathrm{Cl}$} & \multicolumn{2}{|c|}{ Cases } & \multirow[t]{2}{*}{$\mathrm{OR}$} & \multirow[t]{2}{*}{$95 \% \mathrm{Cl}$} \\
\hline & A & B & & & $A$ & B & & & A & B & & & A & B & & \\
\hline \multicolumn{17}{|l|}{ Model I } \\
\hline $\begin{array}{l}\text { Laboratory work in general } \\
\text { Model II }\end{array}$ & 249 & 31 & 0.9 & $0.5-1.5$ & 249 & 13 & 1.5 & $0.7-3.1$ & 248 & 13 & 1.3 & $0.6-2.6$ & 248 & 38 & 1.1 & $0.8-1.6$ \\
\hline Solvents in general & 206 & 25 & 0.5 & $0.2-1.4$ & 206 & 9 & 1.3 & $0.3-6.0$ & 205 & 10 & 3.4 & $1.0-11.9$ & 205 & 33 & 1.7 & $0.7-3.8$ \\
\hline Carcinogenic substances ${ }^{d}$ & 59 & 5 & 0.7 & $0.2-2.0$ & 59 & 2 & 1.1 & $0.2-5.9$ & 59 & 2 & 0.7 & $0.1-3.5$ & 59 & 8 & 0.7 & $0.3-1.8$ \\
\hline Recombinant DNA techniques & 82 & 12 & 1.8 & $0.4-7.7$ & 82 & 2 & $-e$ & - & 82 & 3 & $-e$ & - & 82 & 11 & 0.4 & $0.1-1.1$ \\
\hline All bacteria & 108 & 15 & 0.7 & $0.2-2.8$ & 108 & 2 & $-\mathrm{e}$ & - & 108 & 3 & $-e$ & - & 108 & 19 & 2.7 & $1.0-7.4$ \\
\hline Animals and cell techniques & 156 & 22 & 1.9 & $0.7-4.7$ & 156 & 8 & 2.2 & $0.5-9.1$ & 155 & 6 & 0.5 & $0.1-1.9$ & 155 & 23 & 0.7 & $0.3-1.6$ \\
\hline Radioactive isotopes in general & 123 & 17 & 1.2 & $0.5-2.9$ & 123 & 4 & 0.5 & $0.1-1.9$ & 122 & 4 & 0.6 & $0.1-2.1$ & 122 & 16 & 0.6 & $0.3-1.2$ \\
\hline
\end{tabular}

a Virus exposure excluded due to the low number of exposed pregnancies.

${ }^{b}$ Adjusted for mother's age, gestational age, previous pregnancy not resulting in a live birth, and smoking.

c Adjusted for mother's age, previous pregnancy not resulting in a live birth, and smoking.

${ }^{d}$ Classification of the International Agency for Research on Cancer for carcinogenic compounds, group 1.

${ }^{e}$ Very low risk estimate obtained (not shown). 
0.7-1.9] and 1.6 (95\% CI 0.8-3.3) for high and low birthweight, respectively. Research work with animals and cell techniques, adjusted for gestational age, mother's age, previous pregnancy not resulting in a live birth, and smoking, was, however, associated with a higher risk of high or low birthweight, but the results were not significant (table 3).

Among the first pregnancies, 38 preterm births were found (table 2), 13 for the laboratory workers and 25 for the nonlaboratory workers. For the laboratory workers, the unadjusted odds ratio for preterm births was 1.3 (95\% CI 0.7-2.6), and for women working with any kind of solvent an odds ratio of 3.4 (95\% CI 1.0-11.9) was found for preterm births, with adjustment for mother's age, previous pregnancy not resulting in a live birth, and smoking.

The unadjusted odds ratio for postterm births among the women who had worked with laboratory tasks was 1.1 (95\% CI 0.7-1.7). Work with bacteria $(\mathrm{N}=19)$ showed an odds ratio of 2.7 (95\% CI 1.0-7.4), with adjustment for mother's age, previous pregnancy not resulting in a live birth, and smoking.

\section{Discussion}

Slightly elevated odds were found for high and low birthweights among the women engaged in research work with animals and cell techniques. Work with solvents was associated with preterm births, and work with bacteria, procedures also possibly including work with solvents, was associated with an increased odds of postterm birth. Most of these elevated odds were small and fell within the range of random variability. Hence there is no strong evidence of association, but the fact that our estimates point in the same direction speaks against the assumption that elevated odds ratios were caused at random.

Work in research laboratories carries a risk of contact with potentially embryotoxic and fetotoxic agents. Unfortunately, we have no biological monitoring of exposures to indicate how often a target organ is in fact exposed. The exposure assessment was based on questionnaire information provided by the best experts (the research group leaders) and not the study participants themselves. This procedure reduced the possibility for recall bias and increased confidence in the exposure classification.

Since most of the women worked with different tasks leading to contact with several agents in different combinations, it was difficult to assess the effects of specific biological or chemical agents. We tried to estimate the importance of each exposure by adjusting for the use of other agents. Due to the small numbers, only the main exposure groups could be analyzed, such as "solvents in general" or "all bacteria". For women working with recombinant DNA techniques, no significantly increased risks were found for any of the studied reproduction outcomes.

Exposure to solvents was associated with both preterm and postterm births. This finding may indicate that different types of solvents have different effects on reproduction, that solvents play a role during different time periods of pregnancy, or that solvents disrupt the normal timing of labor.

The reproductive history of the women was taken from the National Medical Birth Register, whose quality has been shown to be high (13). Furthermore, we compared groups expected to have similar social norms in hopes of reducing confounding by these factors. If anything, laboratory women may have a slightly healthier life-style $(5,14)$.

The proportion of respondents in the source cohort was $67 \%$, but after multiple births were excluded, along with women with professions not relevant for the study and pregnancies during leaves of absence, the response rate was $90.3 \%$ for the restricted group used in the analyses. We included only the first birth during the observation period in order to avoid dependence between pregnancies of the same woman.

In the 1970s, and at the beginning of the 1980s, results were published on reproductive outcomes for laboratory workers, although not always for workers in research laboratories; the results mainly concerned spontaneous abortions and malformations $(1,2,9,15,16)$. Some previous studies have indicated associations between specific chemical, physical, and biological agents and different adverse effects on reproduction, such as spontaneous abortions $(1,14,17,18)$, reduction in birthweight (19), malformations (20-23), and time to pregnancy (24-26), while outcomes such as preterm and postterm births have been less well studied $(14,27)$. Both preterm and postterm births are associated with a higher risk of neonatal mortality (28). Increased fetal mortality has been found among postterm infants (28), and cognitive and motor impairments have been found among preterm infants $(29,30)$.

Work in research laboratories differs from work in many other laboratory settings. The work tends to be less standardized with a greater variation and use of highly toxic agents. The high technical standards and safety regulations in many research laboratories may, on the other hand, reduce the risks of hazardous exposures. A recent study of approximately 700 pregnancies of women working in biomedical laboratories and nonlaboratory departments showed, however, elevated risk estimates for preterm births and for infants who were large for their gestational age, especially for boys, for women working with bacteria, and for work with 
solvents (14). The results of our study indicate a slight increase for both large and small babies in association with work with animal research and cell techniques, as well as for small babies in association with solvent exposure, and these results support some earlier findings (3).

In summary, in our study, we observed a slight effect on preterm and postterm births from some specific agents such as solvents and bacteria and a slight increase in the risk estimates for low and high birthweight in association with work with animal research and cell techniques. However, the numbers were small, and therefore any firm conclusions concerning the safety of this work environment are precluded. For a more comprehensive risk assessment of the research laboratory environment, we will also need additional information on other reproductive outcomes, such as spontaneous abortion, stillbirth, perinatal death, and congenital malformation.

\section{Acknowledgments}

Dr Bengt Haglund, Dr Ulrik Kesmodel and Dr Harri Vainio are acknowledged for their valuable discussions during the study.

Funding was provided by The Swedish Foundation for International Cooperation in Research and Higher Education.

\section{References}

1. Axelsson G, Lütz C, Rylander R. Exposure to solvents and outcome of pregnancy in university laboratory employees. Br J Ind Med 1984;41:305-12.

2. Heidam LZ. Spontaneous abortions among laboratory workers; a follow up study. J Epidemiol Community Health 1984; 38:36-41.

3. Taskinen H, Kyyrönen P, Hemminki K, Hoikkala M, Lajunen K,Lindbohm M-L. Laboratory work and pregnancy outcome. J Occup Med 1994;36:311-19.

4. Taskinen H, Chia S-E, Lindbohm M-L, Ching-Ye Hong, Sallmén M, Thein MM. Risk to the reproductive health of working women. Helsinki: Finnish Institute of Occupational Health, 1999. People and work research reports, no 22.

5. Wennborg H, Yuen J, Axelsson G, Ahlbom A, Gustavsson P, Sasco AJ. Mortality and cancer incidence in biomedical laboratory personnel in Sweden. Am J Ind Med 1999;35:382-89.

6. Sambrook J, Fritsch EF, Maniatis T. Molecular cloning; a laboratory manual. 2nd edition. New York (NY): Cold Spring Harbour Laboratory Press, 1989.

7. Wennborg H, Yuen J, Nise G, Sasco AJ, Vainio H, Gustavsson P. Cancer incidence and work place exposure among Swedish biomedical research personnel. Int Arch Occup Environ Health 2001;74:558-64.
8. Adamson SR. Experiences of virus, retrovirus and retroviruslike particles in Chinese hamster ovary (CHO) and hybridoma cells used for production of protein therapeutics. Dev Biol Stand 1998;93:89-96.

9. Axelsson G, Jeansson S, Rylander R, Unander M. Pregnancy abnormalities among personnel at a virological laboratory. Am J Ind Med 1980;1:129-37.

10. Olsen J, Olsen SF. A suggestion for improving intelligibility in multivariate confounder adjustment using alcohol intake and birth weight as an example. Scand J Soc Med 1991; 19:235-41.

11. Hosmer DW, Lemeshow S. Applied logistic regression. New York (NY): John Wiley \& Sons, 1989.

12. Stata Corporation. Stata statistical software: release 6.0. College Station (TX): Stata Corporation, 1999.

13. Cnattingius S, Ericson A, Gunnarskog J, Källén B. A quality study of a medical birth registry. Scand J Soc Med 1990; $18: 143-48$.

14. Wennborg H, Bodin L, Vainio H, Axelsson G. Pregnancy outcome of female personnel in Swedish biomedical research laboratories. J Occup Environ Med 2000;42:438-46.

15. Olsen J. Risk of exposure to teratogens amongst laboratory staff and painters. Dan Med Bull 1983;30:24-8

16. Ericson A, Eriksson M, Källén B, Westerholm B, Zetterström R. Delivery outcome of women working in laboratories during pregnancies. Arch Environ Health 1984;39:5-10.

17. Lindbohm M-L, Taskinen H, Sallmén M, Hemminki K. Spontaneous abortions among women exposed to organic solvents. Am J Ind Med 1990;17:449-63.

18. Windham GC, Shusterman D, Swan SH, Fenster L, Eskenazi B. Exposure to organic solvents and adverse pregnancy outcome. Am J Ind Med 1991;20:241-59.

19. Chen D, Cho SI, Chen C, Wang X, Damokosh AI, Ryan L, et al. Exposure to benzene, occupational stress, and reduced birth weight. Occup Environ Med 2000;57:661-7.

20. Holmberg PC, Hernberg S, Kurppa K, Rantala K, Riala R. Oral clefts and organic solvent exposure during pregnancy. Int Arch Occup Environ Health 1982;50:371-6.

21. McDonald JC, Lavoie J, Côté R, McDonald AD. Chemical exposures at work in early pregnancy and congenital defect: a case-referent study. Br J Ind Med 1987;44:527-33.

22. Cordier S, Ha MC, Ayme S, Goujard J. Maternal occupational exposure and congenital malformations. Scand J Work Environ Health 1992;18:11-7.

23. Khattak S, K-Moghtader G, McMartin K, Barrera M, Kennedy D, Koren G. Pregnancy outcome following gestational exposure to organic solvents: a prospective controlled study. JAMA 1999;281:1106-9.

24. Sallmén M, Lindbohm M-L, Kyyrönen P, Nykyri E, Anttila A, Taskinen $\mathrm{H}$, et al. Reduced fertility among women exposed to organic solvents. Am J Ind Med 1995;27:699-713.

25. Plenge-Bonig A, Karmaus W. Exposure to toluene in the printing industry is associated with subfecundity in women but not in men. Occup Environ Med 1999;56:443-8.

26. Wennborg H, Bodin L, Vainio H, Axelsson G. Solvent use and time to pregnancy among female personnel in biomedical laboratories in Sweden. Occup Environ Med 2001; $58: 225-31$.

27. Rowland AS, Baird DD, Shore DL, Darden B, Wilcox AJ. Ethylene oxide exposure may increase the risk of spontaneous abortion, preterm birth, and postterm birth. Epidemiology $1996 ; 7: 363-8$.

28. Divon MY, Haglund B, Nisell H, Otterblad PO, Westgren M. Fetal and neonatal mortality in the postterm pregnancy: the 
impact of gestational age and fetal growth restriction. Am J Obstet Gynecol 1998;178:726-31.

29. Hutton JL, Pharoah PO, Cooke RW, Stevenson RC. Differential effects of preterm birth and small gestational age on cognitive and motor development. Arch Dis Child Fetal Neonatal Ed 1997;76:75-81.
30. Wolke D, Meyer R. Cognitive status, language attainment, and prereading skills of 6-year-old very preterm children and their peers: the Bavarian Longitudinal Study. Dev Med Child Neurol 1999;41:94-109.

Received for publication: 11 June 2001 